\title{
Who should be responsible for sedation techniques in digestive endoscopy? Reply ${ }^{1}$
}

The January 2005 issue of the journal Revista Española de Enfermedades Digestivas included an original paper by J. Cubiella et al. on behalf of "Sociedad Gallega de Patología Digestiva" (SGPD) (1). The article reported the results of a study on the available sedation modalities, regular method of sedation, and sedation method desired by endoscopists at both public and private endoscopy units in Galicia. Participation in the study was $70 \%$, and so results were considered representative for Galicia, with these being in addition comparable to those of a recent study carried out in Catalonia (2).

That same issue of our Journal included an editorial by Dr. López-Timoneda and Dr. Ramírez-Armengol, from the departments of anesthesiology and endoscopy, respectively, at Hospital Clínico San Carlos in Madrid (3). Although no direct reference is made to the article by Cubiella et al., its content has raised great disquiet and unease among gastroenterology specialists in the Galician Community, as well as in SGPD itself. Statements are made on sedation in gastrointestinal endoscopy that are far from actual daily practice in our country and the international community; indeed, some of them are extremely serious, have potential medico-legal consequences, and may even raise alarm amongst the general population. In the authors' primary conclusion, they demand that "sedo-analgesia (conscious sedation) and deep sedation techniques be exclusively performed by professionals with appropriate qualifications and training for their diligent execution, which is only the case with physicians who are specialists in anesthesiology and resuscitation"; otherwise, they state that "a criminal deed of professional intrusion, as typified in Art. 403 under the criminal law in force" is committed (3).

Although we must respect personal and institutional opinions that may be expressed on controversial areas in a scientific forum, those presented in the aforesaid editorial cannot be accepted as anything more than the authors' own opinion in contrast with criteria issued by scientific societies in our field. Of note, they left out recommendations by international societies of endoscopy and gastroenterology, and an attentive reading of their bibliographical references reveals that they even draw conclusion in opposition to those advocated for by their authors.

Sedo-analgesia is an inseparable part of the endoscopic procedure itself. As a result, endoscopists have developed skills in administering a variety of sedative and analgesic agents to facilitate procedures and enhance patient comfort (4). Sedoanalgesia is carried out routinely in all endoscopic units under the responsibility of

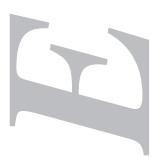

'López Timoneda F, Ramírez Armengol JA. Who should be responsible for sedation techniques in digestive endoscopy? Rev Esp Enferm Dig 2005; 97: 1-6. 
the endoscopist and the control of a specialized nurse; at other times, either within or without this same unit, it may be carried out under the responsibility of an anesthetist. In Spain, training in the skills required to competently carry out endoscopic techniques and sedation within the specialty of gastroenterology is acquired through daily practice during the years of residency training (MIR), in which specific programs are followed in official teaching hospitals, which include participation in other medical and surgical specialties. Recently, the American Society for Gastrointestinal Endoscopy (ASGE) has laid down the requirements to be fulfilled by the training program for gastroenterology residents to train said residents in the techniques of monitoring and administering sedative and analgesic medication for gastrointestinal endoscopy $(5,6)$.

At present, we do not have reference guidelines on endoscopy or sedation from our regional or national societies, although they will doubtlessly be published in the near future. However, guidelines issued by the British Society for Gastroenterology and ASGE specifically refer to the fact that experienced endoscopists may assume responsibility for both sedating the patient and performing the endoscopic procedure $(7,8)$. Moreover, the American Society for Anesthesiology (ASA) itself has contributed to the definition of sedation requirements and methods in gastrointestinal endoscopy by developing the Practice Guidelines for Sedation and Analgesia by Non-Anesthetists (9), whose recommendations have been included in the ASGE's new guidelines on conscious sedation and monitoring (8), and on profound sedation and anesthesia for gastrointestinal endoscopy (10). It must be pointed out that the Practice Guidelines for Sedation and Analgesia by Non-Anesthetists was designed to be applicable to procedures performed in hospitals and free-standing clinics by physicians, as well as dental and other practitioners. Thus, requirements for sedation in endoscopy are fulfilled by adequate professional training and not the possession of an anesthetist degree as sustained by López-Timoneda and Ramírez-Armengol (3).

The objective of sedation and analgesia is to minimize anxiety and pain associated with endoscopic procedures and, as far as possible, the memory of the procedure itself. There are wide variations in the rate and manner of use of sedo-analgesia worldwide (1,2,11-13), which reflect the various drug availabilities and infrastructures, a lack of guides laying down precise indications, differing opinions between endoscopists, and cultural differences among countries (14), with none of this representing any ethical or legal contradictions. Data obtained by the two studies carried out in Spain $(1,2)$ concur with this diversity of use regarding sedation in endoscopy units.

Sedation must be understood as a continuum in which four levels may be distinguished: minimal sedation, moderate sedation (conscious sedation), deep sedation, and general anesthesia (9). Both medical and nursing staff at endoscopy units must be trained and prepared to rescue patients from sedation levels higher than originally induced, especially from ventilatory and cardiac depression, and they must have available the necessary material and human means of support (4-10). These aspects are especially highlighted in the article by Cubiella et al. (1), and would be most useful when demanding of economic control centers the improvements needed in the support of gastrointestinal endoscopy in our Galician Autonomous Community.

Routine care by an anesthesiologist for average-risk patients undergoing standard upper and lower endoscopic procedures is not warranted and is cost-prohibitive (10). The majority of endoscopic procedures with sedation are carried out 
with a moderate level of sedo-analgesia using intravenously administered benzodiazepines (midazolam, diazepam) and/or opiates (meperidine, fentanyl) $(1,2,4$, $7,8,14)$. The use of deep sedation is especially indicated for complex or long procedures. This can be carried out safely by titrated increments of the medication used for moderate sedation, taking extreme care with patient monitoring $(4,7,8,14)$. These drugs are habitually used at the hospital level in situations or procedures other than endoscopy, and therefore their application being restricted to the specialty of anesthesia is to all effects exaggerated, as well as non-viable. On the other hand, there are efficient antagonists such as flumazenil and naloxone that must be part of the stocks at every endoscopy unit. On other occasions, the presence of risk criteria related to sedation may determine the presence of an anesthetist $(9,10)$.

It has recently been demonstrated that propofol, an ultrashort-acting hypnotic agent used for the induction and maintenance of general anesthesia, is useful for the induction of deep sedation in endoscopic procedures when administered on its own or in combination with remifentanil, as it improves patient satisfaction and is associated with a lesser duration of the procedure and shorter recovery when compared to the use of midazolam-meperidine $(9,10,15)$. In some publications, the control of deep sedation with propofol has also been shown to be safe in the hands of nonanesthetist medical staff and qualified nursing staff $(16,17)$. However, we may cite divergent positions between the main American societies of gastroenterology and the societies of anesthesia and anesthetist nurses regarding who should be responsible for deep sedation with propofol (18). We must also point out a recommendation by some authors on a need for constructive discussion between members of both specialties, which would allow an expanded use of propofol by safe and cost-effective means (18).

Propofol has a narrow therapeutic window, which may result in respiratory depression needing ventilatory assistance (general anesthesia), there being no antagonists to reverse its effects. Therefore, to control sedation with propofol it is essential that a person other than the one carrying out the endoscopy be present (9). For these reasons, the introduction of propofol as a substitute for benzodiazepines and opiates in endoscopy could justify an incorporation of anesthetists into these units. Propofol is rarely used at endoscopy units in Galicia, and in the aforementioned study no reference is made to its administration being carried out by endoscopists themselves (1). SGPD supports the demand by endoscopy units that calls for an organized incorporation of specialists in anesthesia into their organization chart, either part-time or full-time. Contrary to the affirmations poured forth in the said editorial, in our area we notice no divergence or lack of collaboration between professionals of our specialty and those of anesthesia. Very much the contrary, efforts by both to jointly overcome daily difficulties is quite obvious.

SGPD was founded in 1970 and its sole objective is to contribute to the progress -within our autonomous region- of this branch of medicine in all aspects of care, teaching, and research. Throughout its more than 35-year long history, it has organized a multitude of courses, conferences, and clinical sessions. It has sponsored multicenter studies, and has collaborated with other scientific societies and healthcare authorities for the consensus of medical criteria and health policies for the attainment of social welfare. SGPD knows the excellent degree of preparation specialists in gastroenterology have in the Galician Autonomous Community, thus recognizing a need for constant effort in the maintenance and improvement of such level. It also guarantees and supports actions as reflected by the results of the study 
published in the January 2005 issue of Revista Española de Enfermedades Digestivas. Sedation and analgesia of patients undergoing digestive endoscopy in Galicia, as administered and controlled by gastroenterologists, is in the view of our scientific society safe and efficient.

\title{
J. Clofent Vilaplana (Vice-President), J. E. Domínguez Muñoz (Secretary), J. Fernández Seara (Past-President) and A. Rey Seijo (President)
}

\author{
by the Sociedad Gallega de Patología Digestiva
}

\section{References}

1. Cubiella J, Lancho A, Echarri A, Ulla JL, Fernández Seara J, on behalf of Sociedad Gallega de Patología Digestiva. Sedation at Endoscopic Units in Galicia: results of the "Sociedad Gallega de Patología Digestiva" inquiry. Rev Esp Enferm Dig 2005; 97: 24-37.

2. Campo R, Brullet E, Junquera F, Puig-Diví V, Vergara M, Calvet X, et al. Sedación en la endoscopia digestiva. Resultados de una encuesta hospitalaria en Cataluña. Gastroenterol Hepatol 2004; 27: 503-7.

3. López Timoneda F, Ramírez Armengol JA. Who should be responsible for sedation techniques in digestive endoscopy? Rev Esp Enferm Dig 2005; 97: 1-6.

4. Cohen J. Conscious sedation for gastrointestinal endoscopy: Recomendations. Up to Date 2004; 12 (3).

5. Guidelines for Training in Patient Monitoring and Sedation and Analgesia. ASGE Training Committee. Gastrointest Endosc 1998; 48 (6): 669-71.

6. Training guidelines for use of propofol in gastrointestinal endoscopy. ASGE Training Committee. Gastrointest Endosc 2004; 60 (2): 167-72.

7. Guidelines for conscious sedation and monitoring during gastrointestinal endoscopy. ASGE Standards of Practice Committee Gastrointest Endosc 2003; 58 (3): 317-22.

8. Guidelines for the use of deep sedation and anesthesia for gastrointestinal endoscopy. ASGE Standarts of Practice Committee. Gastrointest Endosc 2002; 56 (5): 613-7.

9. Bell GD, McCloy RF, Charlton JE, Campbell D, Dent NA, Gear MWL, et al. Recommendations for standards of sedation and patient monitoring during gastrointestinal endoscopy. Gut 1991; 32: 823-7.

10. Practice Guidelines for Sedation and Analgesia by Non-Anesthesiologists: An Updated Report by the American Society of Anesthesiologists Task Force on Sedation and Analgesia by Non-Anesthesiologists. Anesthesiology 2002; 96: 1004-17.

11. Menoli G, Meucci G, Prada A, Terruzzi V, Bartoli A Gullotta Rey, et al. Quality of assurance and colonoscopy. Endoscopy 1999; 31: 522-7.

12. Ristikankare MKO, Julkunen RJK. Premedication for gastrointestinal endoscopy is rare practice in Finland: a nation -wide survey. Gastrointest Endosc 1998; 47: 204-7

13. Faulx AL, Vela S, Das A, Cooper G, Isenberg, Sivak Jr MV, et al. A changing landscape of practice patterns regarding unsedated endoscopy and propofol use: A national survey. Gastrointest Endosc 2004; 59: AB131.

14. Thechniche of upper gastrointestinal endoscopy. In: Sivak MV. $2^{\text {nd }}$ ed. Gastroenterologic Endoscopy. WB Saunders Company, 1999.

15. Martínez-Palli G, Bordas J, Llach J, Ginés A, López A Gambus P, et al. Estudio prospectivo sobre la eficacia de sedoanalgesia en colonoscopia: propofol rifentanilo vs fentanilo-midazolam vs dolantina-midazolam. Gastroent Hepatol 2005; 28 (3): 140.

16. Rex DK, Overley C, Kinser K, Coates M, Lee A, Goodwine BW, et al. Safety of propofol admininstered by registered nurses with gastroenterologist supervision in 2000 endoscopic cases. Am J Gastroenterol 2002; 97 : 1159-63.

17. González-Huix F, Aldeguer X, Fort E, Salinas E, Figa F, Hombrados M, et al Sedation without anesthesiologist in 5250 endoscopic procedures: midazolam vs midazolam+dolantine vs propofol. Gastrointest Endosc 2004; 59: AB13

18. Rex DK. The Science and Politics of Propofol. Am J Gastroenterol 2004; 99: 2080-3. 